\title{
A escrita da história do teatro no Brasil: questões temáticas e aspectos metodológicos"
}

\author{
Rosangela PATRIOTA*
}

\begin{abstract}
RESUMO: Este artigo discute a maneira pela qual a história do Teatro de Arena (São Paulo) tem sido escrita, por meio de depoimentos de seus integrantes e de teses, dissertações e ensaios acadêmicos. Além disso, estabelece um diálogo interdisciplinar entre História e Teatro a partir de questões teóricas e metodológicas.
\end{abstract}

PALAVRAS-CHAVE: história e teatro; história do teatro brasileiro; Teatro de Arena (São Paulo).

Sempre me pareceu que o trabalho de todo historiador está dividido entre duas exigências. A primeira, clássica e essencial, consiste em propor a inteligibilidade mais adequada possível de um objeto, de um corpus, de um problema. É por essa razão que a identidade de cada historiador lhe é dada por seu trabalho em seu território particular, que define sua competência própria.

Roger Chartier, À Beira da Falésia.

Em um processo investigativo envolvendo as interlocuções entre História e Literatura, H istória e Cinema, História e Artes Plásticas, História e Teatro, esta última ainda em proporções reduzidas, se comparada às pesquisas desenvolvidas nas áreas de Letras e de Artes Cênicas, o pesquisador deverá sempre estar atento a alguns pressupostos, pois, além das dificuldades que envolvem essa área de atuação, de acordo com Robert Paris, este profissional, ao contrário de seus colegas que, via de regra, recuperam originais inéditos nos arquivos, dificilmente será o primeiro leitor do documento selecionado. Esta observação é procedente já que, na maioria das vezes, este objeto de pesquisa está inserido em um sistema de referências que "já separou o joio 
do trigo", construindo assim uma hierarquia com relação às obras e aos autores. Diante dessa realidade, sem negar o valor estético das obras, caberá ao estudioso dar a elas um tratamento adequado aos procedimentos inerentes à pesquisa histórica, sempre sujeito a verificações posteriores. ${ }^{1}$

0 enfrentamento do debate historiográfico permite reconhecer a presença de uma memória histórica, ${ }^{2}$ que produz um ordenamento das experiências artísticas, especialmente por meio de noções como moderno, político, universal, clássico, engajado, entre outras, que estruturam a hierarquia e a carga valorativa de obras e de autores. Assim, diante dos problemas apresentados, como desenvolver o trabalho ora proposto? Basicamente, 0 objetivo não é, em hipótese alguma, construir "Histórias de..."; ao contrário, a partir de romances, filmes, peças de teatro, etc., recuperar a historicidade inerente a eles. Devolvê-los ao seu momento e, concomitante a este, buscar constituir um diálogo possível, a partir de séries documentais que permitam uma maior inteligibilidade destes em relação ao processo vivenciado, assim como este fornecerá elementos que auxiliem na compreensão das especificidades do objeto estudado.

Esse cuidado tem sido o ponto de partida para a ampliação desse campo investigativo nas universidades brasileiras. Isso, sem dúvida, atesta a acuidade com que essa área de pesquisa vem se constituindo. Porém, é possível constatar, no âmbito específico das pesquisas, que cada tema e/ou objeto exige do pesquisador um grau de originalidade e de sofisticação no desenvolvimento do trabalho. Esta evidência expõe também um outro dado de extrema significação: o referencial teórico mobilizado pelo estudioso, na maioria das vezes inspira possibilidades e pistas, mas é somente no trato com a documentação que o diálogo entre historiador e o momento histórico selecionado se viabiliza.

N esse sentido, esses embates teóricos e metodológicos com as manifestações artísticas têm permitido aos historiadores brasileiros construírem um importante repertório intelectual de investigação e de análise, relativo a destacados momentos de nossa História e Historiografia, com vistas a contribuir não só com a História Cultural do País, mas sobretudo com a pesquisa contemporânea. 
Em meio a tais abrangências, o diálogo História e Teatro reveste-se de inúmeras implicações, dada a extensão e a diversidade do Teatro, tanto no Brasil quanto no exterior. Dessa feita, as análises, aqui propostas voltar-se-ão para o Teatro Brasileiro encenado durante a ditadura militar, que se tornou referência inequívoca para todos aqueles que se debruçam sobre as interlocuções entre Arte e Política. Dentre elas, uma das questões centrais que alimentam os estudos sobre as décadas de 1960 e 1970 é a seguinte: como construir os diálogos entre História e Estética?

Inicialmente deve-se recordar que a atividade teatral no Brasil é muito diversificada, possui inúmeras matrizes estéticas e teóricas, e geograficamente está dispersa pelo País, considerando que capitais como Porto Alegre (RS), João Pessoa (PB), Salvador $(B A)$, Recife (PE), além de inúmeras cidades no interior dos Estados, abrigaram projetos artísticos e culturais de grande importância. Porém, dado o impacto que o eixo Rio de Janeiro São Paulo tem em divulgar artistas e suas criações, além da força de seus veículos de comunicação, muitos profissionais e/ou companhias deixaram seus lugares de origem e fixaram suas sedes nessas cidades. ${ }^{3}$

Essa constatação também está presente na confecção do debate artístico e intelectual, o que possibilita compreender 0 movimento teórico, documental e metodológico presente na construção de uma História e de uma Historiografia do Teatro Brasileiro, marcadas especialmente por uma concepção de arte capaz de intervir no processo histórico. Para tanto, estiveram envolvidos atores, diretores, dramaturgos, críticos, intelectuais e professores universitários. Estes últimos, inclusive, contribuíram para o estabelecimento de determinadas áreas de interesse em programas de pós-graduação em universidades paulistas e cariocas. Hoje em dia, as pesquisas relativas ao Teatro Brasileiro expandiram-se, ${ }^{4}$ mas as interpretações acerca da produção teatral brasileira, da década de 1970, foram profundamente impregnadas pelos temas e idéias das cenas paulista e carioca. Dessa maneira, como afirmou M ichel de Certeau: "toda pesquisa historiográfica se articula com um lugar de produção socioeconômico, político e cultural. (...) É em função deste lugar 
que se instauram os métodos, que se delineia uma topografia de interesses, que os documentos e as questões que lhes serão propostas, se organizam". 5

Essa evidência é extremamente reveladora para que se compreenda o impacto intelectual das experiências do Teatro de Arena e do Teatro Oficina, ambos sediados na cidade de São Paulo, nos estudos sobre o teatro brasileiro contemporâneo. Porém, há que se considerar: 0 estabelecimento desses referenciais não ocorreu somente por decisões voluntaristas. Embora a cena teatral brasileira tenha, no decorrer do século XX, abrigado a comédia de costumes, 0 drama burguês, ${ }^{6} 0$ teatro de revista, o drama psicológico (dramaturgia brasileira e internacional), tragédias, peças "históricas", espetáculos musicais, entre outros, o denominado teatro político, ou melhor, teatro engajado foi o fio condutor dos estudos sobre o referido período, a partir da trajetória do Teatro de Arena de São Paulo.

TEATRO DE ARENA: MEMÓRIAS E INTERPRETAÇÕES DE SEUS PROTAGONISTAS

Fundado por jovens formados pela primeira turma da Escola de Arte Dramática (EAD) de São Paulo, o Arena teve esta denominação devido à escolha do palco. De acordo com 0 diretor José Renato, a leitura do livro Theatre in the round (Margot Jones) fora fundamental para esta decisão, porque destacava as facilidades e as vantagens, principalmente econômicas, do "palco em arena", principalmente porque 0 Teatro Brasileiro de Comédia (TBC), fundado em 1948 pelo industrial Franco Zampari, trouxera um saldo qualitativo à ribalta paulista. ${ }^{7}$ Se por um lado tal experiência propiciou 0 aparecimento de várias companhias, entre elas Nicete Bruno/Paulo Goulart e Pequeno Teatro Popular, por outro lado muitos grupos, por não possuírem o mesmo suporte financeiro do TBC, acabaram fracassando.

N esse sentido, com as marcações cênicas construídas para a arena, aqueles jovens egressos da EAD realizaram apresentações em diferentes locais, dentre eles o Museu de Arte Moderna de 
São Paulo (M AM). Em 1955, o Arena inaugurou a sua sede na Rua Teodoro Bayma, com o espetáculo A rosa dos ventos, de Claude Spaak, tendo José Renato como administrador e diretor do grupo. Nesse período, intensificou-se a aproximação com o Teatro Paulista do Estudante (TPE), que contava com a participação de Gianfrancesco Guarnieri e Oduvaldo Vianna Filho. Desse contato houve a fusão dos dois grupos, que em 1956 incorporou o diretor teatral Augusto Boal, recém-chegado dos EUA, onde fora cursar Química Industrial, e estudou também Teatro sob a orientação de John Gassner e Lee Strasberg.

Nesse período ocorreram importantes montagens como $M$ arido magro, mulher chata, de Augusto Boal, e Ratos e Homens, de John Steinbeck. Era um repertório eclético que mesclava textos clássicos, peças policiais, comédias inglesas e americanas. Porém, o grande momento desta trajetória ocorreu em 1958, com a encenação de Eles não usam black-tie, de Gianfrancesco Guarnieri e dirigida por José Renato, que redimensionou as expectativas estéticas e políticas do grupo. José Renato salienta:

Acreditávamos que tínhamos coisas significativas a dizer, que nossa contribuição não era apenas relativa à forma, mas principalmente ao conteúdo. M as foi sem dúvida a presença do Teatro Paulista do Estudante que, por assim dizer, trouxe a semente do engajamento que germinou aqui dentro e deu, acredito, os melhores frutos possíveis. Frutos, também, das dúvidas que ainda persistiam no grupo. Posteriormente ao Black-tie abriu-se o Seminário de Dramaturgia, que o Boal dirigiu. E desse Seminário participaram muitos dramaturgos que depois não fizeram peças para o Arena, mas continuaram distribuindo a sua produção por outros teatros. Considero fundamental essa contribuição de preocupação política que vivíamos então no Brasil. Essa preocupação informou o Blacktie, informou Chapetuba e informou, principalmente, Revolução na América do Sul, a peça mais importante daquela época, a meu ver. Com ela realizamos, pela primeira vez, um teatro quase guerrilheiro. Isto é, um teatro em que misturávamos revista, comédia, música ea discussão política dos temas da época. ${ }^{8}$ 
Em fins da década de 50, José Renato aceitou o convite para fazer um estágio no Teatro Nacional Popular com Jean Villar, na França, que o colocou em contato com uma experiência muito sólida de "teatro popular". Retornou em inícios dos anos 60, quando recebeu o convite do Serviço Nacional de Teatro (SNT) para dirigir o Teatro Nacional de Comédia (TNC). Assim, motivado pela perspectiva de realizar espetáculos que um palco em arena não comportariam José Renato encerrou sua participação no Teatro de Arena de São Paulo:

Em 1962 eu me desliguei. Fiquei vinculado ao Arena por outros problemas. Problemas administrativos. M as, orientação quanto a repertório, eu já estava desvinculado. Eu deixei como herança, a última herança, foi a escolha da última peça que eu havia escolhido, que dirigi e que gostava muito. Sai um pouco da linha nacionalista, mas era uma peça tão importante que valeria a pena fazer, que era M andrágora, que foi dirigida pelo Augusto Boal. [...]. Então eu vim para o TNC aqui no Rio e fiz coisas importantes. Foi aqui que eu fiz Boca de ouro, de Nelson Rodrigues. Depois o Pagador de Promessas, de Dias Gomes. ${ }^{9}$

$\mathrm{Na}$ sistematização destes fragmentos percebe-se que a narrativa de José Renato, sobre o Arena, é resultado das experiências e dos anseios por ele alimentados no interior do grupo. Seus depoimentos e análises não versam sobre o conjunto das atividades, mas sobre seu próprio desempenho e sobre os anseios e possibilidades não realizadas.

Por sua vez, o ator e dramaturgo Gianfrancesco Guarnieri, quando se recorda do Teatro de Arena, recorre a referências de sua infância, no Rio de Janeiro, à presença de sua empregada $M$ argarida e à favela na qual ela morava. Aliás, este universo está presente nas peças Eles não usam black-tie e Gimba. Na primeira "a Romana, por exemplo, é de fato uma recriação da mãe de $M$ argarida" ${ }^{10}$ Por sua vez, em Gimba o protagonista, em essência, é muito parecido com "(...) um sujeito muito brigador que tomava conta da Boca de Bicho do Chico. O Gimba namorava a M argarida e por isso conversava muito comigo."

Ao lado desse contato extremamente enriquecedor na infância, o dramaturgo atribuiu à militância, no movimento 
estudantil, um papel importante na discussão sobre a politização da arte:

0 que se fazia era quase um exercício de viver brigando por ideais, mas tudo muito fechado, muito entre nós. Depois de uns três anos de movimento estudantil firme, percebemos que realmente estávamos errando. Depois de uns três anos é que chegamos à conclusão que precisávamos ampliar aquilo, que o movimento estudantil não era só nosso, não era só de uma cúpula e sim de grupos que se formavam em várias capitais, grupos pequenos mas que praticamente se identificavam. E que era necessário então fazer um trabalho sério entre todos os estudantes. Chegamos à conclusão que o movimento cultural e principalmente o movimento artístico seriam um meio eficaz de organização, onde se poderia discutir, reforçar os grêmios, de estruturar diretórios e procurar criar um debate cultural no meio estudantil. ${ }^{12}$ [grifo nosso].

Neste rememorar foram inevitáveis as referências à formação do Teatro Paulista do Estudante (TPE), ao encontro com Ruggero Jacobbi e Oduvaldo Vianna Filho, e às discussões que tinham por finalidade estimular a "dramaturgia nacional", assim como a militância junto ao movimento estudantil e as inqui etações que agitaram o Brasil em fins da década de 1950:

Nunca colocamos nossa carreira individual como objetivo. Nossa meta era outra. Nós não tínhamos grandes responsabilidades [...]. Estou aqui também fazendo um negócio coletivo porque achamos que através desse trabalho podemos nos organizar e desse modo servir à cultura nacional, ajudar a formar uma consciência brasileira [...]. E tudo que acontecia politicamente na época foi importante! Começava a surgir aquele negócio de identidade que seguia todo o processo político, houve a tentativa do golpe, o Juscelino toma posse ou não toma? O Teixeira Lott garante 'Paz e democracia' [...]. Começou-se a falar em nacionalismo, coisa que empolgava a juventude. É verdade, nós não sabemos nada...E o que fazer então? Vamos fazer um curso!' Falamos com Sábato M agaldi, Júlio Gouveia e Décio de Almeida Prado; pedíamos sugestões; fizemos um curso do qual participaram duzentas e tantas pessoas 
[...] era um momento de muita efervescência e tudo era meio fácil porque as pessoas estavam interessadas. As universidades começaram a criar um trabalho mais sólido com preocupações mais orientadas, e de repente começou a se viver no Brasil um clima mais cultural. Era uma coisa geral. Foi justamente nesse estado de coisas que houve a junção do TPE com o Arena. O Zé Renato propôs dar - material para que realizássemos nossos espetáculos nos colégios, ele daria a infra-estrutura, a orientação artística e técnica e, em contrapartida, nós do TPE trabalharíamos como suporte de cast para o Teatro de Arena, que já era profissional. ${ }^{13}$ [ grifo nosso].

De maneira contínua, os acontecimentos históricos pontuam a narrativa de Guarnieri. M esmo recordando as saídas de José Renato e de Vianinha do grupo, foi o fechamento do Arena pelo golpe militar de 1964 que norteou os comentários sobre a interdição do espetáculo 0 filho do cão, de sua autoria, ea montagem de Tartufo, de Molière. Nos mesmos termos, tais acontecimentos foram referências para comentar a Fase dos M usicais, período em que o T eatro de Arena encenou Arena conta Zumbi e Arena conta Tiradentes.

Tal procedimento, articulando as realizações estéticas do Arena à conjuntura política e social, encontra-se também nas avaliações do ator e diretor Paulo José, que integrou a companhia na década de 1960 . Em meio a várias recordações, destacou a euforia nacionalista do governo JK que, do ponto de vista estético, traduziu-se em uma valorização da "fala e do tipo físico brasileiro". Da fusão entre a perspectiva política do TPE com o método Stanislavski, trazido por Augusto Boal, surgiu a primeira referência de engajamento do Teatro de Arena de São Paulo. Esta nova concepção teve um papel importante na composição do elenco:

O grupo começou a fazer chamada de testes para elenco. Abria de uma outra forma esse tipo de convocação. A própria convocação já sugeria que não precisava trazer essas características clássicas do teatro: não precisava ser loiro, de olhos azuis, um metro e oitenta, bela voz, não precisava ser uma pessoa elegante [...]. 
Esse pequeno grupo começou a atrair pessoas: Flávio M igliaccio, Dirce Migliaccio que vieram lá de Vila Mazzei, uma coisa suburbana [...] ligados a uma família de pintores - o M igliaccio é um pintor quase primitivo - quer dizer, algumas ligações com a arte mas $[\ldots]^{14}$

Esta constatação é extremamente importante, porque realiza uma aproximação, no nível social, entre um perfil de artista, considerado "superado" pelo TBC, e os novos atores do Arena. Paulo José, exatamente por enfatizar temas como "dramaturgia nacional" e articulação entre arte e política, elegeu o momento denominado como Fotografia, ${ }^{15}$ no qual foram encenadas Eles não usam black-tie, Chapetuba Futebol Clube e Revolução na América do Sul, como fundamental para a constituição de uma unidade na trajetória do Arena. Ao lado desta ponderação, o autor destacou a importância de artistas como Guarnieri, Vianinha e Boal para a realização das atividades do grupo, e em especial para a confecção do grande marco de identificação do Teatro de Arena na H istória do Teatro no Brasil: a defesa do teatro e da dramaturgia nacional.

Ao lado desses depoimentos, o Teatro de Arena de São Paulo teve entre seus membros intelectuais que construíram reflexões sobre os trabalhos do grupo e seus significados. Como observou Paulo José - Gianfrancesco Guarnieri, Oduvaldo Vianna Filho e Augusto Boal nortearam muitas das atividades do Arena. No entanto, estes dois últimos, junto com a criação artística (peças, direção de espetáculos e atuações neles) produziram textos nos quais, além de tecer interpretações sobre teoria teatral em geral, e sobre teatro brasileiro em particular, analisaram o significado histórico do Arena.

Oduvaldo Vianna Filho integrou o grupo entre 1956 e 1960, oriundo do Teatro Paulista do Estudante (TPE). Neste período, como ao longo de sua breve vida, produziu textos que procuraram dar inteligibilidade aos momentos políticos e estéticos por ele vivenciados. ${ }^{16}$ Em 1958 escreveu um ensaio visando a construir uma periodização do teatro brasileiro contemporâneo, tendo como eixo a noção de "modernização", com vistas a compreender o impacto das produções do TBC no 
cenário teatral do período. Se, por um lado, Vianinha via com entusiasmo as atividades do TBC, por outro lado, no que se referia ao seu papel político, tinha várias restrições, porque este não se mobilizava em torno de temas e ações que pudessem contribuir para a organização do Brasil contemporâneo:

A resposta vem dos jovens na sua maioria, e são os jovens que compõem a maioria do teatro brasileiro: um teatro nacional. Um teatro que procure a realidade brasileira, que apreenda o sentido do seu desenvolvimento e que lute ao lado dele. [...]. Este ano, neste sentido, é de importância enorme. Eles não Usam BlackTie, de Gianfrancesco Guarnieri, é o símbolo de todo um movimento de afirmação do teatro brasileiro. Além disso? Jovens diretores: Antunes Filho, Flávio Rangel, Augusto Boal, Fernando Torres, José Renato, [...] a fundação de um Seminário de Dramaturgia de São Paulo, um Laboratório de Interpretação, pesquisando uma forma nacional da arte de representar, tudo 0 mais. De acordo. Ainda é um início. M as início para chegar ao mais alto dos objetivos: teatro brasileiro. ${ }^{17}$

Em meio a essas considerações, Vianinha analisou o trabalho do grupo, as expectativas advindas das escolhas temáticas, a opção pelo palco em arena e as implicações políticas que estavam contidas ou projetadas. No entanto, embora reconhecesse essas conquistas, deixou o grupo em 1960 e transferiu-se para o Rio de Janeiro, onde com Leon Hirszman, Chico de Assis, Carlos Estevam Martins, entre outros, fundou o Centro Popular de Cultura, posteriormente o CPC da UNE. Dessa maneira, mesmo mantendo identificação estética e política com o Teatro de Arena, Vianna justificou sua saída devido à incapacidade do grupo em atingir parcelas consideráveis da população:

A urgência de conscientização, a possibilidade de arregimentação da intelectualidade, dos estudantes, do próprio povo, a quantidade de público existente, estavam em forte descompasso com o Teatro de Arena enquanto empresa. Não que o Arena tenha fechado seu movimento em si mesmo; houve um raio de ação comprido e fecundo que foi atingido com excursões, com conferências etc. M as a mobilização nunca foi muito alta porque 
não podia ser muito alta. E um movimento de massas só pode ser feito com eficácia se tem como perspectiva inicial a sua massificação, sua industrialização. É preciso produzir conscientização em massa, em escala industrial. Só assim é possível fazer frente ao poder econômico que produz alienação em massa. [...]. O Arena, sem contato com as camadas revolucionárias de nossa sociedade, não chegou a armar um teatro de ação, armou um teatro inconformado. Guarnieri, Boal podem ou não escrever peças de ação, mas um movimento de cultura popular não pode depender de talentos pessoais. [...] U ma empresa que seja sustentada pelo povo para, objetivamente, ser obrigada a falar e ser entendida por esse povo. Um movimento de cultura popular usa o artista corrente, usa uma ideologia de espetáculo que precisa pertencer à empresa, e não aos seus representantes individuais. Nenhum movimento de cultura pode ser feito com um autor, um ator etc. É preciso massa, multidão. ${ }^{18}$

Para Vianinha, as criações do Teatro de Arena de São Paulo deveriam estar em consonância com um projeto maior de mobilização da sociedade brasileira, no sentido de dinamizar a "revolução democrático-burguesa" e estimular as transformações históricas que se faziam necessárias a partir das análises dos segmentos progressistas. De acordo com suas avaliações, 0 momento era de intensificar a ação cultural, a fim de que ele compartilhasse de uma efervescência revolucionária então vislumbrada.

Já Augusto Boal, embora compartilhasse de preocupações semelhantes no âmbito político e social, privilegiou em seus escritos a trajetória artística do Teatro de Arena. Essa iniciativa e - caminho analítico adotado contribuíram para que suas interpretações se tornassem referências para estudos posteriores sobre a mencionada companhia teatral, especialmente 0 texto "Etapas do Teatro de Arena de São Paulo", que integra o livro Teatro do 0 primido e outras poéticas políticas.

Nesse trabalho, partindo do pressuposto de que os elencos do teatro brasileiro dividiam-se entre clássicos e revolucionários, ${ }^{19}$ Boal estabeleceu o lugar do Arena em nosso teatro. Para tanto, periodizou as suas atividades em quatro etapas: Primeira Etapa - 
Não Era Possível Continuar Assim; Segunda Etapa - A Fotografia; Terceira Etapa - Nacionalização dos Clássicos; Quarta Etapa Musicais.

$\mathrm{N}$ a Primeira Etapa o autor registrou o ano de 1956 como o início da fase realista, vista como evidente negação do teatro que até então se praticava na cidade, isto é, as críticas voltaram-se para o TBC, mais especificamente sobre seu repertório e o estilo interpretativo de seus atores, no qual predominava muito mais a composição da personagem que a sua dimensão psicológica. Em outros termos, esta análise expunha a insatisfação do segmento mais politizado da cena paulista com os espetáculos em cartaz na década de 1950, ao mesmo tempo em que estabelecia o surgimento do Teatro de Arena como um contraponto nascido dos espaços deixados pelo TBC:

O Arena devia responder com peças nacionais e interpretações brasileiras. Porém, peças não havia. Os poucos autores nacionais de então preocupavam-se especialmente com mitos gregos. N elson Rodrigues chegou a ser ovacionado com a seguinte frase, que consta da orelha de um dos seus livros: "Nelson cria, pela primeira vez no Brasil, o drama que reflete o verdadeiro sentimento trágico-grego da existência." Estávamos interessados em combater o italianismo do TBC, mas não ao preço de nos helenizarmos. Portanto, só nos restava utilizar textos modernos realistas, ainda que de autores estrangeiros.

0 realismo tinha, entre outras vantagens, a de ser mais fácil de realizar. Se antes usava-se como padrão de excelência a imitação quase perfeita de Guielgud, passávamos a usar a imitação da realidade visível e próxima. $A$ interpretação seria tão melhor na medida em que os atores fossem eles mesmos não-atores.

Fundou-se no Arena o Laboratório de Interpretação. Stanislawsky foi estudado em cada palavra e praticado desde as nove da manhã até a hora de entrar em cena. ${ }^{20}$

Por sua vez, a etapa denominada A Fotografia teve o seu início marcado pela encenação de Eles não usam black-tie, em 1958, e estendeu-se por quatro anos, vindo a se encerrar em 1962. N esse período, muitos dramaturgos foram lançados, dentre eles: Oduvaldo Vianna Filho (Chapetuba Futebol Clube), Roberto 
Freire (Gente como a Gente), Edy Lima (A Farsa da Esposa Perfeita), Augusto Boal (Revolução na América do Sul), Francisco de Assis (0 Testamento do Cangaceiro), Benedito Ruy Barbosa (Fogo Frio). Esse momento, para Boal, significou o fechamento das portas do Arena a dramaturgos estrangeiros e a acolhida de temas e textos brasileiros:

Esta etapa coincidiu com o nacionalismo político, com o florescimento do parque industrial de São Paulo, com a criação de Braślia, com a euforia da valorização de tudo nacional. As peças tratavam do que fosse brasileiro: suborno no futebol interiorano, greve contra os capitalistas, adultério em Bagé, vida subumana dos empregados em ferrovias, cangaço no N ordeste e a conseqüente aparição de Virgens e Diabos, etc. 0 estilo pouco variava e pouco fugia do fotográfico, seguindo demasiado de perto as pegadas do primeiro êxito da série. Eram as singularidades da vida o principal tema deste ciclo dramatúrgico. ${ }^{21}$

M esmo reconhecendo a importância estética e política da iniciativa, 0 autor descreve como um processo natural 0 encerramento da etapa em que as trincheiras em torno do autor brasileiro deveriam ser firmadas. Nesse sentido, por intermédio de observações genéricas, aproximou-se de justificativas estéticas, via identidade entre palco e platéia, como o argumento para a inserção de dramaturgos estrangeiros no repertório do Teatro de Arena, em particular, aqueles considerados como clássicos pelo pensamento ocidental: A Mandrágora (Maquiavel), 0 Noviço (Martins Penna), 0 M elhor Juiz, o Rei (Lope de Vega), Tartufo (M olière), 0 Inspetor Geral (Gogol). Contudo, essas peças foram encenadas a partir das perspectivas sociais do momento, isto é, houve uma adaptação delas às necessidades da conjuntura brasileira.

Finalmente, com vistas a dar unidade à trajetória do Teatro de Arena, Augusto Boal articulou a essas fases os Musicais, período considerado como destruidor de convenções teatrais, que poderiam se tornar obstáculos ao desenvolvimento estético das artes cênicas. 
Procurava-se mais: contar uma história não da perspectiva cósmica, mas sim de uma perspectiva terrena bem localizada no tempo e no espaço: a perspectiva do Teatro de Arena e de seus integrantes. A história não era narrada como se existisse autonomamente: existia apenas referida a quem a contava. ${ }^{22}$

Apesar de Boal não ter se debruçado exaustivamente sobre as opções estéticas, vale destacar que os Musicais foram provenientes da experiência carioca desse diretor na montagem do espetáculo 0 pinião. ${ }^{23}$ Considerado "símbolo da resistência" ao golpe, este trabalho abriu uma vertente estética e política, que foi amplamente utilizada nos períodos subseqüentes e deu origem à Fase dos Musicais, na qual se destacaram Arena conta Zumbi, Arena conta Tiradentes, Arena conta Bolívar.

Sob esse aspecto, a união entre a canção de protesto e o teatro engajado permitiu a criação de novos caminhos estéticos. A elaboração do "sistema coringa" e a aproximação com as reflexões de Brecht sobre o "teatro épico", entre outros procedimentos, permitiram que o Arena redimensionasse sua atuação artística e política. A escolha de "situações históricas", para refletir sobre o tema da liberdade, propiciou a constituição de uma "identidade" entre palco e platéia, que se tornou um dos marcos da resistência artística à ditadura instaurada em 1964.

Após outros musicais (Arena canta Bahia, Praça do Povo, entre outros), foram encenados La M oschetta, de A. Beolco, 0 círculo de giz caucasiano, de B. Brecht, etc. Em junho de 1968, 0 Teatro de Arena promoveu a I Feira Paulista de Opinião, com a encenação dos textos: 0 Líder, de Lauro C. M uniz; 0 Sr. D outor, de Bráulio Pedroso; Animália, de Gianfrancesco Guarnieri; A receita, de Jorge Andrade; Verde que te quero verde, de Plínio Marcos, e A lua muito pequena e A caminhada perigosa, de Augusto Boal.

No início de 1970, Boal encenou o Teatro Jornal e vislumbrou novas perspectivas artísticas e políticas com a criação do N úcleo 2 do Teatro de Arena. Porém, o acúmulo de dívidas da companhia e a sua prisão impossibilitaram a continuidade dos trabalhos e fizeram com que o Arena de São Paulo encerrasse suas atividades em agosto do mesmo ano, deixando inacabadas, 
porém com várias sugestões, as perspectivas da arte teatral sob os governos autoritários.

\section{O TEATRO DE ARENA DE SÃO PAULO NA HISTORIOGRAFIA DO TEATRO BRASILEIRO}

A estrutura narrativa organizada pelos escritos de Augusto Boal, a pouco e pouco, tornou-se a base a partir da qual foram escritas as interpretações historiográficas confeccionadas a posteriori. Assim como em reflexões contemporâneas a esses acontecimentos, como a do crítico e historiador do teatro Sábato $M$ agaldi, no livro Panorama do T eatro Brasileiro, a encenação de Eles não usam Black-Tie tornou-se um marco não só na trajetória do Arena, mas para o teatro contemporâneo no Brasil. Mesmo tendo sido escrito na década de $1960,{ }^{24}$ o mencionado estudo debruçou-se sobre as atividades artísticas do Teatro Oficina e do Teatro de Arena, enfatizando particularmente o trabalho de dramaturgia. No caso deste último, Black-Tie é assim avaliada:

0 baluarte do movimento nacionalista foi o Teatro de Arena de São Paulo, depois que a peça Eles não U sam Black-Tie, de Gianfrancesco Guarnieri (nascido na Itália mas vindo para o Brasil com um ano de idade), permaneceu doze meses em cartaz, embora numa sala de 150 lugares. Acreditou-se que os espectadores quisessem ouvir seus problemas em linguagem brasileira. Como plataforma radical, o elenco passou a oferecer apenas peças nacionais, a maioria delas escrita pelos próprios atores e saídas do Seminário de Dramaturgia, que se organizou como departamento do Teatro de Arena. Nestas últimas temporadas, era de esperar que se sucedessem ali alguns dos melhores e alguns dos piores textos brasileiros, já que, freqüentemente, na faina criadora, diversos se completaram no correr dos ensaios e guardavam ainda, na estréia, o sabor de fruto temporão. Não condenamos o exagero: sabe-se que, nas revoluções, os erros dificilmente podem ser evitados, e era importante testar a eficácia da dramaturgia brasileira. 0 Teatro de Arena, com esse ardor nacionalista, trouxe numerosas contribuições, e a mais positiva foi sem dúvida a de quebrar o tabu que cercava 0 autor brasileiro. ${ }^{25}$ 
Por sua vez, Sonia Goldfeder, em seu estudo "Teatro de Arena e Teatro Oficina - o Político e o Revolucionário", no que se refere ao Teatro de Arena, analisa o projeto estético e ideológico da companhia, a partir das fases apresentadas por Augusto Boal. Dessa maneira, sua investigação assume o ano de 1958 e a montagem de Eles não usam black-tie como marcos da nacionalização e o início da fase da Fotografia, qualificada como o momento mais radical de exaltação nacional e de visão mistificadora do "povo", na medida em que forjou um discurso próprio, um projeto independente que the conferiu uma autonomia diante de outras manifestações do período em que Eles não usam black-tie foi uma bandeira de luta que inaugurou uma tradição de "teatro político" no País.

$\mathrm{Na}$ esteira da análise de Boal, Goldfeder avaliou que a primeira fase, Fotografia, situou a singularidade, enquanto por intermédio da Nacionalização dos Clássicos o Arena caminhou para a universalidade. Nesse processo, a síntese fez necessária a Fase dos M usicais.

Outros trabalhos de grande importância, que recorriam à temporalidade elaborada por Augusto Boal foram Zumbi e Tiradentes, de Cláudia Arruda Campos. Embora se detenha exaustivamente em análise das peças Arena conta Zumbi (1965) e Arena conta Tiradentes (1967), a autora elabora um histórico sobre a trajetória do grupo à luz da periodização mencionada.

N esse percurso, a crítica teatral M ariângela Alves de Lima, no ensaio História das Idéias, ${ }^{26}$ também realizou um balanço cronológico das atividades do grupo e assumiu, desde o início, 0 papel decisivo de Boal nos destinos do Teatro de Arena. Estabelecido este aspecto, enfocou as preocupações contidas em duas frentes. A primeira estaria na formação de um público e na captação de novos contingentes para 0 trabalho teatral. A segunda revelava a preocupação com a interpretação do ator ao lado de um olhar crítico sobre a dramaturgia brasileira disponível, especialmente após 1958;

O Arena se compromete com a invenção de uma dramaturgia enraizada na história do País. É dessa história, "enquanto 
acontece", que o grupo vai extrair os textos que precisa para reanimar um trabalho que estava próximo a um ponto de estrangulamento.

Precariamente pode-se denominar o trabalho de Arena, a partir de Black-tie, como uma linha de nacionalismo crítico. Isso porque o nacionalismo, nesse caso, não tem conotação estreita de um ufanismo da coisa própria. Não se pode, portanto, desvincular o nacionalismo da crítica, na avaliação do trabalho do Arena. ${ }^{27}$

Dessa feita, após situar o Arena no cenário teatral brasileiro, Mariângela Alves de Lima refez o percurso da companhia por intermédio do caminho traçado por Boal, com vistas a destacar a nacionalização dos clássicos e os musicais, em consonância com 0 processo político brasileiro. Movimento semelhante foi também adotado por Lúcia Maria Mac Dowell Soares, em sua monografia "O Teatro Político do Arena e de Guarnieri".

Com o intuito de circunstanciar as atividades do Teatro de Arena, a autora traça um panorama de suas atividades, mais uma vez obedecendo às fases definidas por Boal. No entanto, ao abordar esta periodização, ao contrário dos demais autores, Lúcia M ac Dowell observou:

Boal fala das fases do Arena como se fossem inevitáveis e não faz referências nem às suas crises estéticas, nem às influências do golpe militar de 64. Segundo ele, tudo ocorre de acordo com uma providencial ordem natural das coisas, em que o Arena ia atravessando as únicas etapas possíveis.

Tal visão é insuficiente. E certo que o Arena sempre caracterizou-se por uma resistência cultural e uma tendência à reformulação de seus passos anteriores. Porém é faltar com a verdade a difusão da idéia de que o TA encontrou nos musicais a forma ideal que estaria sendo perseguida. [...]. No entanto, a questão assim colocada não responde a nada. $\mathrm{Na}$ verdade, o Arena já trazia em si, mesmo antes das possíveis implicações na arte decorrentes do golpe de 64, um esgotamento de fórmulas estéticas. Sem dúvida, a companhia teria que encontrar uma resposta formal a esta questão. M as nada determinava que fosse o musical, forma que "aliava a uma trama relativamente simples 
o envolvimento emocional da platéia". As idéias encontravam sua expressão conotativa na música, dispensando portanto o arranjo minucioso das peripécias da ação dramática. ${ }^{28}$

Lúcia M ac Dowell, de maneira muito perspicaz, constatou a maneira pela qual Augusto Boal construiu sua cronologia, destituída de conflitos. Todavia, não aprofundou esta discussão porque as implicações de tal procedimento não eram o objeto privilegiado de sua discussão.

Por fim, Edélcio Mostaço, em "Teatro e Política: Arena, Oficina e Opinião - uma interpretação da cultura de esquerda", mesmo trazendo para sua análise questões teóricas referentes ao debate da esquerda do período, realizou uma reflexão sobre o Teatro de Arena com uma estrutura semelhante à dos demais trabalhos mencionados, isto é, salientando marcos importantes como a fusão com o TPE, a chegada de Augusto Boal, a estréia de Black-tie, entre outros.

Assim, partindo da premissa de que os trabalhos da companhia construíam, da maneira direta ou indireta, um diálogo com as teses do Realismo e, algumas vezes, com 0 próprio Realismo Socialista, M ostaço analisou as fases propostas por Boal por este referencial teórico:

A fase dos musicais iniciada com Zumbi foi justificada por Boal como uma necessidade de sintetizar o particular, exacerbado na época nacionalista, e o universal, utilizado durante a fase de nacionalização dos clássicos; "tínhamos de encontrar o particular típico".

É sabido que este conceito estético foi divulgado por Georg Lukács. Sua retomada, nestas alturas das preocupações estético/políticas dentro do Arena, não é fortuita. Para quem já tinha se defrontado com as principais teses do realismo socialista, com as constituintes de universalidade da dramaturgia pré-burguesa, burguesa e aristocrática, chegar às teses lukacsianas representa um percurso natural, uma espécie de programa definido. De um lado o debruçamento sobre episódios retirados da História (como os que caracterizam os textos escritos em coringa) obrigava o encenador a possuir uma teoria da História, não apenas para nortear-se quanto à possível exemplaridade de um ou outro episódio e sobre ele trabalhar 
como, ao estabelecer as correlações passado-presente, poder distinguir entre as constituintes mais gerais de um e outro período. Além do mais o momento histórico (crise das lideranças) estava a exigir um mais sério defrontamento com a função do indivíduo na história. Como é possível ver nas atuais preocupações do Arena, o caráter político desta função adquiriu a momentosa tarefa de articular uma convocação de atuação prática imediata. Neste processo de instantaneização com a função do indivíduo na história dissipiram-se, porém, os contornos "humanistas" da fase da nacionalização dos clássicos, aqueles contrapontos teóricos brechtianos que tornaram o Arena uma barreira estética ao simplismo do CPC.

A preocupação em filiar o processo criativo do Arena a uma corrente estética definida implicou também investigá-lo do ponto de vista ideológico, em especial a partir das conseqüências advindas do golpe de 1964. Por fim, como "canto de cisne" das atividades, Mostaço recuperou o teatro-jornal, nitidamente inspirado pelos grupos de agit-prop (agitação e propaganda), surgidos no decorrer do processo revolucionário russo de 1917 e com os quais Boal tomara contato durante seus estudos sobre teatro, nos Estados Unidos. Nesse sentido, à semelhança de Mariângela Alves de Lima, esta reflexão buscou apreender momentos distintos da trajetória do grupo e confrontá-los com motivações ideológicas e políticas de seu tempo.

Embora existam outros trabalhos que elaborem um perfil do Teatro de Arena, ${ }^{30}$ apresentamos aqueles que se tornaram referências obrigatórias entre os pesquisadores e os que ajudaram a construir e divulgar uma concepção definida do que foi a História do Teatro de Arena de São Paulo.

A MEMÓRIA HISTÓRICA E AS INTERPRETAÇÕES SOBRE O TEATRO DE ARENA DE SÃO PAULO

Após a sistematização de depoimentos de artistas e de estudos que se debruçaram sobre essa experiência histórica, algumas evidências saltam aos olhos. A primeira diz respeito às diferentes narrativas e às distintas apreensões dos acontecimentos 
ou do processo de trabalho. A segunda é relativa à escolha dos temas abordados e dos momentos privilegiados.

Por exemplo, para José Renato, o foco privilegiado foi 0 momento de criação do grupo, a opção pelo palco em arena e a encenação de Eles não usam black-tie. A partir daí, o seu rememorar desprendeu-se do coletivo e privilegiou o estágio no Teatro N acional Popular (TNP) de Jean Vilar, em Paris, sua saída do grupo e a ida para o Teatro Nacional de Comédia, no Rio de Janeiro. Embora reconheça que a preocupação política foi a grande contribuição ao teatro que se fazia em São Paulo, o diretor não se comprometeu com a proposta de intervenção, especialmente ao considerar que em 1962 as suas expectativas teatrais não mais estavam na Rua Teodoro Bayma.

Gianfrancesco Guarnieri, por sua vez, ao ser convidado a recordar suas atividades à frente do Teatro de Arena, em primeiro lugar recuperou o contato que teve com habitantes das favelas do Rio de Janeiro e, na seqüência, sua atuação no movimento estudantil, a criação do TPE, 0 ingresso na companhia. 0 sucesso de Black-tie, a perspectiva de um teatro nacional e a idéia de engajamento foram elementos importantes para compreender os marcos referenciais do autor. Nesse aspecto, o diálogo entre o fazer teatral e a conjuntura política foi a base do trabalho de Guarnieri junto ao grupo, bem como as suas peças e as respectivas encenações.

Aliás, o vínculo Teatro e Sociedade foi também o eixo da narrativa do ator e diretor Paulo José que, ao refletir sobre a proposta artística da companhia, destacou a maneira pela qual ela libertou 0 ator do physique du rôle e da composição interpretativa do Teatro Brasileiro de Comédia.

Diferentemente, Oduvaldo Vianna Filho, falecido em 1974, e Augusto Boal, em vez de externarem suas opiniões somente por meio de depoimentos e entrevistas, propuseram-se a refletir teoricamente sobre a importância do Teatro de Arena. 0 primeiro enfatizou a contribuição das atividades do grupo para o teatro brasileiro e para a história cultural do País. 0 segundo não só discutiu o trabalho, como também construiu uma periodização que organizou as fases e o significado do Arena, do 
ponto de vista de sua história interna e de suas implicações com a conjuntura política dos anos 1950 e 1960.

Ao lado disso, é importante ressaltar a ênfase dada à atmosfera sociopolítica do Brasil de então, às influências teóricas explicitamente assumidas, e principalmente à busca de significados para as atividades do grupo, tanto em uma dinâmica interna de trabalho, quanto nas influências recebidas, como pelas experiências sociais vivenciadas por seus artistas.

Estas idéias também são presenças constantes na historiografia relativa ao Teatro de Arena. Aliás, a primeira constatação refere-se ao fato de que todos os estudos existentes sobre o grupo aceitam a periodização proposta pelos agentes, em particular a construída por Augusto Boal no ensaio intitulado "Etapas do Teatro de Arena de São Paulo". Nele, o autor estabelece com precisão as fases desenvolvidas pelo grupo. São elas: 1) não era possível continuar assim; 2) a fotografia; 3) nacionalização dos clássicos; 4) musicais.

Como foi demonstrado, as variantes dos trabalhos ocorrem nas diferentes interpretações sobre 0 grupo. Porém, em momento algum os estudiosos questionam-se a respeito do lugar em que estas interpretações ocorrem. ${ }^{31}$ Nestas circunstâncias, mais uma vez revela-se a originalidade e a importância das reflexões de Carlos Alberto Vesentini acerca desse procedimento:

A unificação de percepções divergentes advindas de fontes opostas, que se chocaram, confluíram ou se anularam no processo mesmo da luta, torna-se essencial para a possibilidade de construção da ampla temporalidade característica da memória do vencedor. Aceito e estabel ecido este tempo peculiar, a seqüência de fatos, temas, crise e marco legitimador/definidor (base a permitir a organização de todo o conjunto) torna-se atrativa por si só, recebendo e absorvendo quaisquer novas informações ou estudos.

Estabelecem-se núcleos orientadores de memórias, em torno de questões, de problemas, a atraírem as análises e a proporem revisões. Podem ser recuperados por aquele conjunto abrangente, de modo que também se integrem naquela ampla memória, no seu tempo (e sua cisão, em dois momentos maiores), mesmo quando trazidos por participantes vencidos ou 
descartados no conjunto do processo, por autores saídos de grupos que efetivamente se envolveram com a história. ${ }^{32}$

Apesar de estas observações dizerem respeito a um momento muito específico do processo histórico brasileiro, Revolução de 1930 e seus temas, as implicações teóricas e metodológicas destas idéias são extremamente significativas e amplas, pois abrem possibilidades de questionamentos da periodização já cristalizada, que com o passar dos anos transformara-se no próprio acontecimento.

À luz destas proposições verifica-se que, do ponto de vista político, os projetos do Teatro de Arena foram derrotados, já que se vinculavam aos setores denominados progressistas. Todavia, no que diz respeito à história do teatro brasileiro, eles tanto se tornaram marcos capazes de redefinir uma proposta com caráter nacional, como estimularam a confecção de uma dramaturgia brasileira que tornara as camadas subalternas da população protagonistas das ações dramáticas.

N uma perspectiva cronológica do processo, o Arena surgiu como o responsável pela implementação de uma arte identificada com a realidade nacional de caráter revolucionário, no período anterior a 1964, quando o tema da revolução democráticoburguesa mobilizava os setores comprometidos com os interesses nacionais. Entretanto, com a tomada do poder pelos militares, as atividades qualificadas como revolucionárias, a pouco e pouco foram se transformando em exercícios de "resistência democrática". Por sua vez, o próprio golpe de Estado surgiu, na maioria dos estudos comentados, como um marco na trajetória do grupo e não dimensionado do ponto de vista histórico. Assim, o acontecimento é circunstanciado sem que efetivamente suas conseqüências estéticas e políticas sejam exploradas.

Já nos depoimentos e/ou entrevistas existem vários aspectos norteadores deste rememorar, evidentemente mediado pelo período em que o depoente e/ou entrevistado atuou no Teatro de Arena. No entanto, a produção historiográfica tem elidido esta multiplicidade e em seu lugar surgem as fases estabelecidas pelo texto de Augusto Boal. 
Embora Boal tenha sido o integrante que mais tempo permaneceu na companhia (1956-1971), não foram as suas memórias, mas as suas análises teóricas que deram estrutura de continuidade à trajetória do Teatro de Arena. Um contraponto ilustrativo a essa evidência é o fato de Gianfrancesco Guarnieri (responsável pela inserção da companhia na história do teatro brasileiro como fundadora de uma dramaturgia nacional) resgatar o processo a partir de seu trabalho como autor, em vez de fazêlo dentro de uma perspectiva mais geral, tanto mais que, ao ser convidado a rememorar o fim do grupo, a sua referência é a saída de Augusto Boal do País.

Um outro exemplo digno de menção é a entrevista de Luiz Carlos Arutin concedida a Richard Roux. N ela, 0 ator relembrou os seus esforços para manter as atividades do Arena como grupo, e a luta para manter 0 teatro na Rua Teodoro Bayma. ${ }^{33}$ No entanto, para os componentes do Arena histórico, essas atividades, desenvolvidas na década de 1970, não são consideradas como pertencentes à trajetória do grupo.

No que diz respeito à historiografia, verificamos que todos os trabal hos consultados aceitaram a periodização construída por Augusto Boal, bem como os argumentos que a fundamentaram. As diferenças existentes entre esses estudos dizem respeito, inicialmente, à utilização da documentação: ora privilegiam as críticas existentes sobre os espetáculos, ora destacam os depoimentos e as análises dos participantes. No entanto, independentemente da opção feita, o que se evidencia é a ausência de um tratamento crítico do "corpus" documental. Isto pode ser dito porque, na maioria das vezes, a documentação é usada como se fosse portadora (sem maiores esforços analíticos) das interpretações mais corretas sobre os acontecimentos. Em outros casos ilustram, com maior riqueza de detalhes, os eventos.

Nesse sentido, uma outra discussão diz respeito às diferenças que envolvem, de um lado, os "testemunhos", e de outro, as interpretações. Carlos Alberto Vesentini, ao problematizar esta questão, recorreu à distinção entre história tradicional e história moderna ou revisionista, a partir dos argumentos da historiadora Emília Viotti da Costa: ${ }^{34}$ 
A autora nota as dificuldades envolvidas nos "fatos conhecidos", como até mesmo a possibilidade do desaparecimento de quaisquer fatos, a favor da interpretação - "esquemas novos". Análises vazias, saídas do puro esquema, no ar, seriam um grande risco. E o fato perderia sua historicidade, seqüência necessária. Outro lado do mesmo problema, para Viotti da Costa, seria lastrear esses estudos renovadores, numa insuficiente crítica das fontes e dos fatos delas saídos, herdando-se, nesse caso, elementos de uma imagem deformada, superficial e imediata dos acontecimentos. 0 que não significa recusa. 0 caminho parece aberto e, nele, enfrentar esses senões torna-se uma tarefa prática.

Agora, o ponto específico trazido por essa distinção e colocado à prática do especialista, algo como seu ofício, estaria na felicidade e técnica necessárias para clivar a interpretação do fato, de forma muito refinada. Não se trata mais, ao meu ver, de fato e idéia: aqui a análise nova se entende por interpretação, surge a posteriori e implica ciência.

0 arsenal tecnológico de nosso ofício elaboraria num grau superior fontes e fatos em bruto, como que dando-lhes certa qualidade científica, liberando-os daquele mundo de paixões e percepções parciais, interessadas, de forma a garantir à análise, desde então e sobre aquela base, pontos firmes de apoio. E versões contemporâneas, friso, em que a disputa turva e, mais, impede a visão de conjunto. I solá-las, cotejá-las, depurá-las seria equivalente, suponho eu, a abrir caminho à ciência e às suas interpretações. N estas, lastreadas, resi diria o conhecimento.

Existem duas nuanças que comentarei neste momento, a me parecerem problemáticas nesta distinção classificadora, a partir deste ponto especial, visto logo acima. A primeira delas já foi apresentada. Expulsar roupagens subjetivas, a idéia imediata do fato, é uma pretensão extremamente complicada. Se advém de pensar em separado, como distintos, idéia e fato, pelo qual ela apenas o "invadiria", no decorrer das ações, por quem as vive, a complicação só aumenta. Esta subjetividade da idéia não se coloca como exterioridade, "fora" e colada a ele. Ou ela reside no próprio interior do fato, constituindo-o, ou ele não nos aparece como fato. Em segundo lugar, como decorrência, salvo pelo gongo do nosso esforço, esse procedimento se encontra com o movimento próprio ao fato, no caminho da unicidade, a partir da qual toma certo ar despido, de coisa bruta. Poderíamos, 
ironicamente, por isso mesmo, cair na sua força de atração, gravitando em torno dele. Nenhuma novidade, mas ainda não o tínhamos visto precisamente neste terreno da ciência. ${ }^{35}$

Verificados estes impasses envolvendo a utilização dos testemunhos e das interpretações nas análises históricas, deve-se indagar: de que modo os historiadores de ofício podem contribuir para o estudo da história e da historiografia do teatro brasileiro?

Primeiramente, deve ser observada a própria formação do profissional em História, uma vez que sua especificidade é constituída em torno de "métodos e técnicas de pesquisa". I sso se torna mais evidente à medida que passamos a reconhecer a existência da H istória da Literatura, História do Teatro, História da Música, História do Cinema, entre outras tantas histórias. Desta maneira, no momento em que a área de H istória propõe-se ao estudo interdisciplinar, ela trava também um diálogo crítico com a historiografia forjada no séc. XIX, tanto em relação aos temas consagrados ou pertinentes à história como área de conhecimento, quanto no que toca ao diálogo com essas histórias específicas, elaboradas pelos especialistas dos temas e não pelo historiador de ofício.

Dessa feita, respeitando a historicidade e o lugar de sua escrita, as conclusões que podem ser retiradas, especificamente em relação à produção historiográfica do Teatro de Arena são extremamente interessantes, pois no que se refere aos trabalhos apresentados no balanço historiográfico, a primeira questão diz respeito à sua origem. Aqueles que foram produzidos na área de Artes e/ou Letras possuem uma abordagem que vai consolidando uma maneira de compreender e interpretar a história do teatro no Brasil. Partindo de uma perspectiva cronológica dos acontecimentos os autores realizam uma exaustiva pesquisa documental, e de posse deste material incorporam-no às narrativas, construindo assim as trajetórias dos grupos estudados. N esse caso específico encontram-se as análises de Sábato Magaldi e Cláudia Arruda Campos.

Por outro lado, as reflexões que tiveram orientações ou idéias provenientes da área de Filosofia procuraram munir-se de um repertório teórico, com o intuito de interpretar criticamente 
as atividades da companhia. Esta perspectiva está presente nas discussões realizadas por Edélcio Mostaço e Maria Lúcia Mac Dowell Soares. Nelas emergem referências às idéias de Walter Benjamin, em particular o texto "O autor como produtor", recém-editado no Brasil na época da confecção dos trabalhos, sendo que às discussões de M aria Lúcia Soares foi incorporado o tema do ISEB à luz do ensaio de M aria Sylvia Carvalho Franco, "O Tempo das llusões".

A presença destas referências teóricas fez com que muitas vezes, os autores desconsiderassem tanto o momento da escrita dos textos quanto a historicidade dos próprios acontecimentos. Este procedimento fez com que reflexões interessantes acabassem perdendo a dimensão histórica dos objetos de análise, e as conclusões anunciadas, ao não circunstanciarem as discussões, não se realizaram como tais.

Dessa maneira, refletir sobre a construção do conhecimento histórico, nas mais diversas áreas, e neste caso específico, no campo teatral, sem dúvida contribuirá para a ampliação do debate tanto entre os historiadores como entre os especialistas da área, principalmente atentando para a contribuição que os historiadores da cultura poderão dar aos diálogos interdisciplinares. No entender de Hunt,

Os historiadores da cultura não devem substituir uma teoria redutiva da cultura enquanto reflexo da realidade social por um pressuposto igualmente redutivo de que os rituais e outras formas de ação simbólica simplesmente expressam um significado central, coerente e comunal. Tampouco devem esquecer-se de que os textos com os quais trabalham afetam 0 leitor de formas variadas e individuais. Os documentos que descrevem ações simbólicas do passado não são textos inocentes e transparentes; foram escritos por autores com diferentes intenções e estratégias, e os historiadores da cultura devem criar suas próprias estratégias para lêlos. Os historiadores sempre foram críticos com relação a seus documentos - e nisso residem os fundamentos do método histórico. ${ }^{36}$

N estas circunstâncias, refletir sobre o impacto da pesquisa histórica nas demais áreas do conhecimento, bem como analisar 
a maneira pela qual tal iniciativa poderá contribuir para o alargamento da formação e de nossas inquietações é uma instigante tarefa para o "historiador de ofício", a quem caberá a ampliação do referencial, tanto do ponto de vista temático quanto teórico e metodológico, ao lado de uma contínua tensão entre hipóteses, objetos e pesquisas, pois como bem lembrou Lynn H unt, "os historiadores sempre foram críticos com relação a seus documentos", e esta dimensão crítica talvez seja a perspectiva original e estimulante do ofício do historiador.

PATRIOTA, Rosandela. The writing of the history of the theater in Brazil: thematic questions and methodological aspects. História, São Paulo, v.24, n.2, p.79-110, 2005.

ABSTRACT: This article debates the way Arena Theater (São Paulo) history has been written, by its members' testimonies and academics thesis, dissertations and essays. Besides, it establishes a dialogue between History and Theater from theoretical and methodological questions.

KEYWORDS: History and theater; Brazilian theater history; Arena theater (São Paulo);

\section{NOTAS}

\footnotetext{
* Professora do Instituto de História da Universidade Federal de Uberlândia (MG). CEP: 38412-100. e-mail: rpatriota@triang.com.br.

${ }^{1}$ PARIS, R. A imagem de um operário no século XIX pelo espelho de um vaudeville. Revista Brasileira de História. São Paulo, ANPUH/Marco Zero, v.8, n.15, p.61-69, set. 1987- fev. 1988.

${ }^{2} \mathrm{O}$ conceito de "memória histórica" utilizado fundamenta-se na concepção trabalhada por Carlos Alberto Vesentini: "por memória histórica entendo uma questão bastante precisa, refiro-me à presença constante da memória do vencedor em nossos textos e considerações. Também me remeto às vias pelas quais essa memória impôs-se tanto aos seus contemporâneos quanto a nós mesmos, tempo posterior e especialistas preocupados com o passado. Mas com
} 
um preciso passado - já dotado, preenchido, com os temas dessa memória” VESENTINI, C.A. A instauração da temporalidade e a (re)fundação na História: 1937 e 1930. Revista Tempo Brasileiro, Rio de Janeiro, v.1, out-dez, 1986, p.104.

${ }^{3}$ A lista dos que fizeram esse caminho é longa. Em relação ao Rio Grande do Sul, na passagem da década de 1950 para a de 1960, podemos recordar a vinda para São Paulo e/ou Rio de Janeiro dos seguintes artistas: Fernando Peixoto, Ítala Nandi, Lílian Lemmertz, Antônio Abujamra, Paulo José, Lineu Dias, entre outros. Do Recife, vieram Paulo Mendonça, Ilva Nino, etc. No que se refere a artistas mais jovens, não se deve esquecer que Luís Mello, Simone Spoladore, Felipe Hirsch, Luiz Carlos Vasconcellos, Mário Bortolotto e vários outros saíram de suas cidades natais para fixar residência e disputar o mercado de trabalho em São Paulo e no Rio de Janeiro. O mesmo ocorreu com a Companhia Armazém de Teatro, de Londrina - Pr, que se transferiu para o Rio de Janeiro.

${ }^{4}$ Nesse aspecto, há importantes programas de pós-graduação em Teatro e/ou Artes Cênicas sediados na Universidade Federal da Bahia (UFBA) e Universidade do Estado de Santa Catarina (UDESC), e na área de História, as atividades desenvolvidas pelo Núcleo de Estudos em História Social da Arte e da Cultura (NEHAC) junto à Linha de Pesquisa História e Cultura do Programa de Pós-Graduação em História Social da Universidade Federal de Uberlândia (UFU).

5 CERTEAU, M. de. A Escrita da História. Rio de Janeiro: ForenseUniversitária, 1982, p.66-67.

${ }^{6}$ Os dramas que apresentam a forma clássica, isto é, com respeito às unidades de tempo, espaço e ação, desenvolvem conflitos bem definidos entre protagonista e antagonista e são tradicionalmente conhecidos como drama burguês. Para maiores informações consultar PAVIS, P. Dicionário de Teatro. São Paulo: Perspectiva, 2001.

${ }^{7}$ Deve-se entender como saldo qualitativo o surgimento de uma companhia de teatro que contribuiu para a profissionalização das artes cênicas na cidade, tanto no que se refere ao trabalho do ator, do diretor, do cenógrafo, quanto na atualização do repertório dramático a ser encenado. Para maiores informações sobre o TBC consultar: GUZIK, A. TBC: Crônica de um Sonho. São Paulo: Perspectiva, 1986.

${ }^{8}$ Ciclo de Palestras sobre o Teatro Brasileiro (José Renato). Rio de Janeiro: INACEN, 1987, v.4, p.22.

${ }^{9}$ Depoimentos VI. Rio de Janeiro: MEC-SEC-SNT, 1981, p.99.

10 "Gianfrancesco Guarnieri". In: KHOURY, S. (org.). Atrás da Máscara I. Rio de Janeiro: Civilização Brasileira, 1983, p.16.

${ }^{11}$ Idem, p.16.

${ }^{12}$ Idem, p.23. 
${ }^{13}$ Idem, p.30-31.

${ }^{14}$ Depoimento de Paulo José. In: ROUX, R. Le Theatre Arena (São Paulo 19531977) - Du "théâtre en rond" au "théâtre populaire". Aix: Université de Provence, 1991, p.437.

15 Fotografia é uma das fases da periodização feita por Augusto Boal da trajetória do Teatro de Arena de São Paulo. Ela recebeu esse nome devido à encenação de peças que buscavam apresentar no palco problemas vivenciados pela sociedade brasileira do período.

${ }^{16}$ As produções artística e teórica de Oduvaldo Vianna Filho foram estudadas de maneira mais detalhada em minha tese de doutorado intitulada Vianinha um dramaturgo no coração de seu tempo. São Paulo: Hucitec, 1999.

${ }^{17}$ VIANNA FILHO, O. Momento do teatro brasileiro. In: PEIXOTO, F. (org.). Vianinha: Teatro - Televisão - Política. São Paulo: Brasiliense, 1983, p.24.

${ }^{18}$ VIANNA FILHO, O. Do Arena ao CPC. In: PEIXOTO, F. (org.). Vianinha: Teatro - Televisão - Política. São Paulo: Brasiliense, 1983, p.93.

${ }^{19}$ Esta distinção é estabelecida da seguinte maneira: "são clássicos não os que montam obras clássicas, mas os que procuram desenvolver e cristalizar um mesmo estilo através de seus vários espetáculos. Neste sentido, o senhor Oscar Ornstein seria um produtor 'clássico', já que seus espetáculos procuram aperfeiçoar sempre a novela radiofônica em termos vagamente teatrais. 'Clássico'foi o TBC dos áureos tempos: muita gente ainda sofre de saudades da elegância de todos os seus espetáculos: Ralé e Antígona, Goldoni e Pirandello, eram formosos. A formosura era a suprema meta clássica daquelas neves de antanho. Clássico, portanto, é qualquer elenco que se desenvolva e se mantenha dentro dos limites de qualquer estilo, louvável ou pecaminoso. Assim, o 'teatro de caminhão' dos vários Centros Populares de Cultura mantinha-se numa linha clássica.

Já o Teatro de Arena de São Paulo elabora a outra tendência, a do teatro revolucionário - e eu estou sempre falando no bom sentido. O seu desenvolvimento é feito por etapas que não se cristalizam nunca e que se sucedem no tempo, coordenada e necessariamente. A coordenação artística e a necessidade social". BOAL, A. Teatro do Oprimido e outras Poéticas Políticas. 2.ed., Rio de Janeiro: Civilização Brasileira, 1977, p.175-176.

${ }^{20}$ Idem, p.177-178.

${ }^{21}$ Idem, p.179-180.

${ }^{22}$ Idem, p. 184.

${ }^{23}$ Este espetáculo foi escrito por Vianinha, Paulo Pontes e Armando Costa, e protagonizado por Nara Leão, depois substituída por Maria Bethânia, Zé Keti, e João do Vale.

${ }^{24}$ O livro Panorama do Teatro Brasileiro de Sábato Magaldi possui três edições: a primeira é de 1962 (São Paulo: Difel); a segunda é de 1977 (Rio de Janeiro: 
SNT, DAC, FUNARTE, MEC); e a terceira edição é de 1997 ( São Paulo: Global).

${ }^{25}$ MAGALDI, S. O Texto no Teatro Moderno. In: Panorama do Teatro Brasileiro. 3.ed. São Paulo: Global, 1997, p.214 e 300.

${ }^{26}$ LIMA, M. A. de. História das Idéias. In: Dionysos. Rio de Janeiro: MEC, DAC-FUNARTE, SNT. out, 1982, p.40-41.

${ }^{27}$ Idem, p.45.

28 SOARES, L.M.M.D. O Teatro Político do Arena e de Guarnieri. In: Monografias/1980. Rio de Janeiro: MEC/SEC/INACEN. 1983, p.27-28.

29 MOSTAÇO, Edélcio. Teatro e Política: Arena, Oficina e Opinião - uma interpretação da cultura de esquerda. São Paulo: Proposta Editorial, 1982, p.83-84.

${ }_{30}$ Sábato Magaldi, por sua vez, em 1984, publicou na coleção "Tudo é História”, da Editora Brasiliense, o livro Um palco brasileiro: O Arena de São Paulo. Este trabalho merece registro porque, em uma linguagem acessível e em um texto de fácil compreensão, o autor apresentou a trajetória do Teatro de Arena de São Paulo, destacando os principais espetáculos, os momentos que significaram mudanças nas atividades do grupo (a fusão do Arena com o TPE, a chegada de Augusto Boal, por exemplo), além de narrar a opção pelo palco em arena feita pelo diretor José Renato.

Um outro trabalho que merece menção é o de Richard Roux, Le Theatre Arena (São Paulo 1953-1977) - Du "théâtre en rond" au "théâtre populaire". Aix: Université de Provence, 1991, que possui um corpus documental de grande valia, pois de um total de 751 páginas que compõem o volume, quase 500 são destinadas às entrevistas que o autor realizou com os integrantes do Arena e o perfil biográfico de cada artista.

O referido trabalho é dividido em quatro partes. A primeira corresponde a uma panorama do teatro brasileiro anterior ao surgimento do Arena. No primeiro capítulo, Roux aborda o movimento teatral dos anos 1930 e 40, destacando o teatro profissional (as grandes companhias e atores renomados como Procópio Ferreira, Jayme Costa e Dulcina de Moraes); o teatro de revista, a chanchada e o repertório destas companhias. Em outro momento o autor constrói uma panorama sobre o teatro amador (Teatro Universitário, O Teatro do Estudante do Brasil, Os Comediantes, com particular destaque para a encenação de Vestido de Noiva, de Nelson Rodrigues, sob direção de Ziembinski, O Teatro de Arte do Rio de Janeiro, além do Grupo de Teatro Experimental de São Paulo). Na conclusão do capítulo, é apresentada ao leitor a trajetória do Teatro Brasileiro de Comédia ao lado da Companhia Cinematográfica Vera Cruz.

O segundo capítulo, intitulado Breve Panorama Histórico, está dividido em subcapítulos. Sob a designação "de 1930 a 1954: de Getúlio a Getúlio" são abordados "o populismo de GV", a sua deposição em 1945, seu retorno ao 
poder em 1950 e seu suicídio em 1954. Seguem-se os anos Kubitschek (a política econômica de JK e a construção de Brasília; o ISEB e o fim do mandato), os governos Jânio Quadros e João Goulart e o golpe de 64 . Posteriormente são apresentados: a ditadura militar, o movimento estudantil, a oposição contra o regime, além da repressão à universidade, a doutrina de segurança nacional e a derrota do movimento estudantil.

A segunda parte do livro, denominada "Um teatro em arena", está dividida em quatro capítulos, sendo que primeiramente são consideradas as experiências em palco "arena" antes do surgimento do Arena. No segundo capítulo abordase a constituição do Teatro de Arena: a criação com José Renato; o TPE e o seu encontro com o Arena; a chegada de Augusto Boal; a fase realista e a existência de uma crise ideológica e econômica.

O terceiro capítulo propõe uma discussão estética e dos elementos que a compõem: temas realistas, a inclusão e a exclusão do espectador (emoção e distanciamento) e o contato deste com os atores, além de avaliar a utilização da técnica como iluminação, sonoplastia e os odores. No quarto capítulo é apresentada a peça Eles não usam black-tie, bem como as pesquisas em torno de uma expressão brasileira e os seminários de dramaturgia.

Na terceira parte do livro, Roux destina um capítulo para analisar o estágio de José Renato em Théâtre National Populaire (TNP) de Jean Vilar. No capítulo seguinte resgata-se a atuação de Augusto Boal, as atividades em arena no Rio de Janeiro, os musicais como o show Opinião, Arena conta Zumbi e Arena conta Tiradentes. Com o intuito de concluir o panorama sobre o trabalho do Teatro de Arena, destacam-se a Feira Paulista de Opinião, O Teatro-Jornal, e as atividades subseqüentes ao exílio de Boal e a saída de Guarnieri, entre outros.

Por fim, o último capítulo se propõe a refletir acerca da noção de "teatro popular" e, sob este aspecto, resgata as atividades de José Renato, de Oduvaldo Vianna Filho no CPC, de Augusto Boal e o Teatro do Oprimido, além das experiências de Maria Helena Kühner.

Após a apresentação dos temas e das questões abordadas por Roux, devemos dizer que o referido trabalho é de extrema valia, um exercício de sistematização e apresentação para uma universidade e um público estrangeiros, da trajetória do Teatro Brasileiro neste século. Para realizar tal intento, o autor organizou a produção elaborada no Brasil sobre o tema, o que propiciou a constituição de um material extremamente útil para consultas, bem como a publicação das entrevistas, de um valor incalculável para as pesquisas sobre teatro brasileiro.

$\mathrm{Na}$ linha de depoimentos e no estabelecimento cronológico da trajetória do Teatro de Arena de São Paulo encontra-se também o livro de Izaías Almada, Teatro de Arena: uma estética de resistência (São Paulo: Boitempo, 2004).

31 Este procedimento foi constatado também no estudo feito sobre a dramaturgia de Oduvaldo Vianna Filho. Esta descoberta permitiu que 
lançássemos novas questões à documentação disponível. Assim sendo, o resultado da pesquisa (tese de doutorado) possibilitou propor novas periodizações ao processo, ao lado da construção de interpretações originais que, sem dúvida, deram contribuições ao debate sobre a produção artística de Vianinha, bem como abriram novas possibilidades de reescrever a história do teatro no Brasil.

${ }^{32}$ VESENTINI, C.A. A Teia do Fato. São Paulo: Hucitec, História Social, USP, 1997, p.163.

${ }^{33} \mathrm{O}$ prédio era alugado, e os proprietários queriam vendê-lo. Posteriormente foi comprado pelo INACEN e se tornou Teatro Experimental Eugênio Kusnet. Luiz Carlos Arutin fala de várias tentativas infrúteras de manter o Arena em sede própria. Inclusive resgata um espaço que fora cedido pela Prefeitura de São Paulo, à época que Sábato Magaldi era secretário da Cultura, mas a cessão não foi realizada. Seu depoimento é, devemos ressaltar, ratificado pela narrativa de Sábato Magaldi em depoimento a Richard Roux.

34 O autor utilizou dois artigos: "Sobre as origens da República" e "A Proclamação da República", que originalmente tinham sido publicados nos Anais do Museu Paulista, tomos XVIII e XIX respectivamente. Estes textos foram republicados no livro Da Monarquia à República: momentos decisivos 3.ed. São Paulo: Brasiliense, 1985.

${ }^{35}$ VESENTINI, C.A. A Teia do Fato. São Paulo: Hucitec, História Social, USP, 1997, p.84-85.

${ }^{36}$ HUNT, L. A Nova História Cultural. São Paulo: Martins Fontes, 1992, p.18.

Artigo recebido em 06/2006. Aprovado em 07/2006. 